\title{
¿Podemos escuchar las voces de los grupos subalternos en los archivos?
}

\author{
Brígida von Mentz
}

$\mathrm{L}$ as preguntas que el historiador se plantea sobre el pasado lo conducen a buscar determinada información. Por lo general, son cierto tipo de registros los que, a su vez, lo llevan a transmitir determinada visión de la historia. He intentado comprender los cambios que han ocurrido en el mundo del trabajo en México, por lo que me ha interesado escuchar sobre todo las voces de los grupos subalternos; he buscado reconstruir algunos aspectos de su vida diaria, desde el siglo XVI hasta el XX. Así, en este breve testimonio quiero mencionar el tipo de documentos encontrados en las pesquisas que he llevado a cabo en algunos archivos (públicos y privados, locales, nacionales y extranjeros) al tratar de descubrir huellas que, de manera directa o indirecta, me permitieran reconstruir aspectos de la vida de los trabajadores comuneros, campesinos, indígenas, esclavos de procedencia africana en el medio rural; de artesanos, técnicos y de grupos subalternos urbanos, operarios de ingenios azucareros, de empresas mineras o de ciudades industriales en el Porfiriato.
La visión del pasado, como una historia de bronce vinculada con el poder político y el devenir de los gobernantes, está relacionada con los registros que el mismo Estado ha considerado dignos de preservar y aquellos que ha mandado destruir. Esto lo percibimos muy claramente en México con la larga historia de eliminación sistemática de ciertas fuentes incómodas o despreciadas, como las crónicas anteriores al imperio mexica de la época de Izcóatl y Moctezuma, los códices indígenas destruidos en el siglo XVI por los religiosos europeos, y el abandono de una inmensa cantidad de papeles en municipios y edificios gubernamentales en la época moderna. Se preservan, en cambio, documentos que generalmente permiten a las agencias estatales recuperar las voces de gobernantes ilustres, generales triunfadores, connotados diplomáticos o las de la clase social de propietarios que acuden ante el notario a registrar una nueva compañía, a comprar o vender haciendas, esclavos, minas, residencias urbanas, entre muchos otros bienes. Sin embargo, una mirada oblicua a documentos notariales, particulares $\mathrm{u}$ 


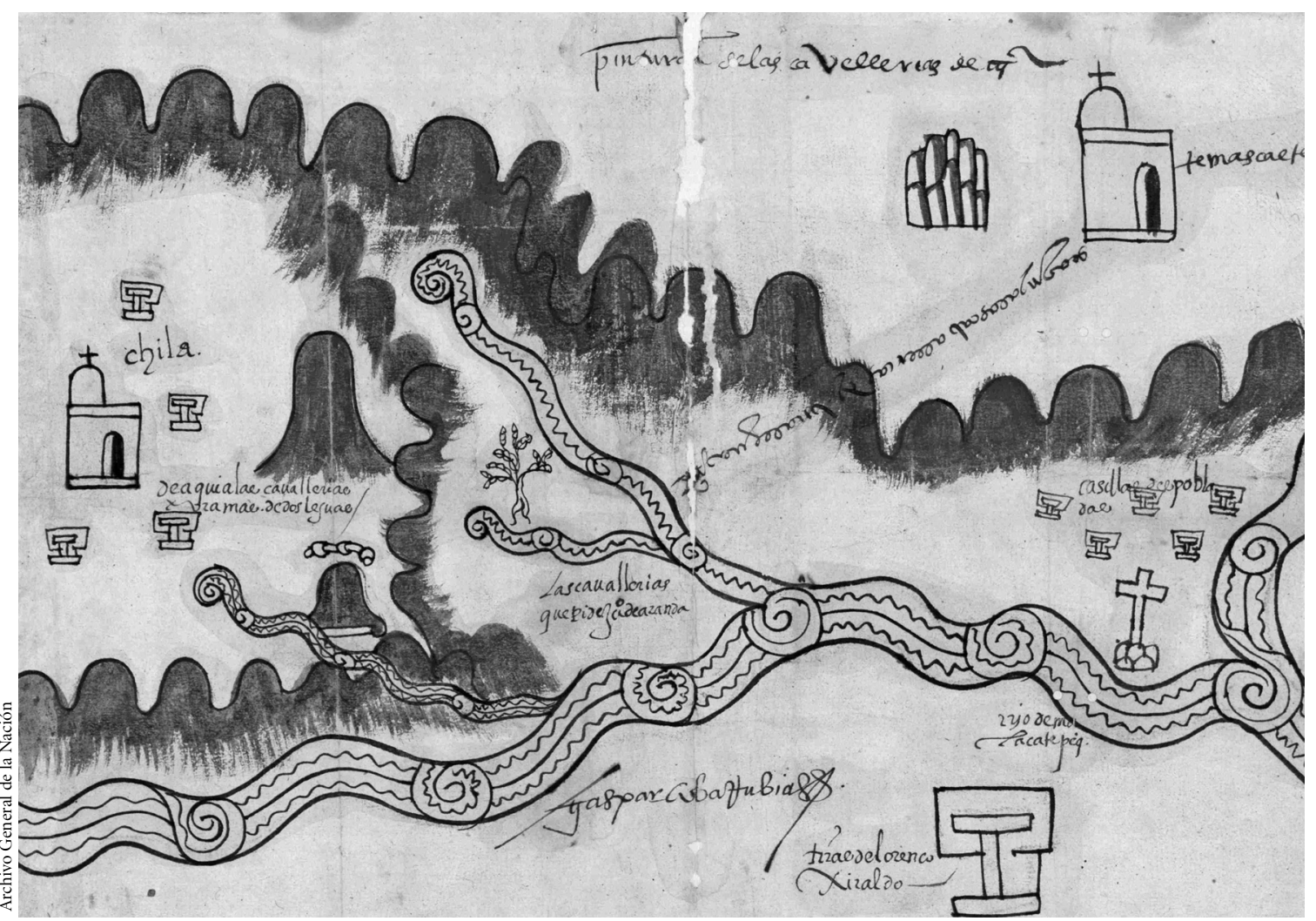

Tierras de Juan Azanda comarcanas a Temascaltepec y Chila, Estado de México, [1579]. Mapoteca, AGN.

oficiales y emanados con intereses estatales permite, muchas veces, recuperar alguna valiosa información de los grupos subalternos. Para empezar, veamos por ejemplo la situación de la población indígena de la zona de la actual ciudad de Cuernavaca hacia 1540.

En la Biblioteca del Museo Nacional de Antropología e Historia existen unas listas de casas con información de los habitantes de cada unidad doméstica escritas en 1540 en lengua náhuatl, pero con grafía latina. Se trata de voluminosos censos —algunos fragmentos están, además, dispersos en otros archivos de París y Cracovia ${ }^{1}$ - que nos permiten entrar a los palacios señoriales y a las moradas de mandones, así como a casas humildes y jacales de los campesinos. Podemos conocer de esta manera a

\footnotetext{
${ }^{1}$ Mayores detalles en Mentz, 2003.
}

miles de personas que vivían en la región de Cuauhnáhuac durante el gobierno del primer virrey, fecha en la que los europeos aún no imponían todos los cambios que unas décadas más tarde acabarían por transformar las formas indígenas de organización social.

¿Cómo es posible que tales documentos se hayan elaborado en fechas tan tempranas? La explicación radica en las controversias entre la Corona española (representada en la Nueva España por el virrey) y el conquistador, Hernán Cortés. Cuando el virrey Antonio de Mendoza llegó a fines de 1536, traía órdenes explícitas de indagar si el conquistador no se había excedido en sus privilegios como marqués y de revisar los pueblos y vasallos a los que tenía derecho. Esto explica el hecho de que entre 1536 y 1544 se hayan mandado hacer matrículas y cuentas de los "vasallos indígenas del marqués" en la zona que actualmente conforma el estado de Morelos, para 
averiguar si no contaba con más vasallos de los concedidos. Esos censos se realizaron, por lo tanto, en esos años, y para ello se recurrió a los nobles y principales indígenas de Cuauhnáhuac que, de hecho, seguían gobernando sus pueblos. Ellos elaboraron las matrículas en lengua "mexicana", como lo hacían desde antes de la llegada de los europeos, de acuerdo con sus prácticas antiguas de vigilancia y control de la población. La única diferencia con sus costumbres de llevar registros pictográficos catastrales fue que en esta ocasión no pintaron las casas, sus moradores, sus tierras y sus tributos en forma pictográfica, sino que las escribieron en "mexicano" (náhuatl) con las grafías latinas que habían aprendido de los franciscanos asentados en Cuernavaca desde 1525. Así, en ese ambiente, surgieron estas matrículas o censos que nos muestran cómo toda la jurisdicción estaba dividida en un sinnúmero de parcialidades en orden jerárquico; es decir, en cada una de ellas había mandones locales que respondían ante los superiores. Esos mandones indígenas menores conocían cada caserío por aislado y alejado que estuviera, y llevaban cuenta del número de habitantes, si los hijos habían salido para casarse, si había llegado algún anciano viudo o cuántas personas habían fallecido en esas casas.

Las cuentas exactas de cada unidad doméstica y de las tierras de cultivo disponibles eran datos importante para la recaudación y contabilización del tributo. Por eso, como decía el cronista y religioso dominico fray Diego Durán, tenían mandones para todo y tanta "orden y policía” que ni un habitante se les escapaba (Durán, 1984, vol. I: 88).

En esta fuente, además, se escuchan las voces de los migrantes, por ejemplo, cuando en el censo se preguntaba si se quedarían en las parcelas que ocupan o si se regresarían al lugar de origen de sus abuelos, que habían sido los que llegaron a este lugar. Aunque se trata de una fuente muy voluminosa y repetitiva — consta de listas de casas, que se mencionan una por una, sus moradores, la cantidad de hijos o de parientes que allí vivían, el tamaño de la parcela que cultivaban y la cantidad de tributo que pagaban-, es fundamental para reconstruir la vida de los señores y comuneros indígenas antes de la llegada de los españoles y unas décadas después (Mentz, 2006).

Otro tipo de fuentes procedentes del Archivo General de la Nación (AGN) ha permitido escuchar las voces de los habitantes de pueblos menores de la misma zona. Por ejemplo, hacia 1671 unos indígenas apresados en la cárcel de Cuernavaca escribían a sus compañeros en México una carta en náhuatl. En ese momento ocurría un profundo conflicto contra los franciscanos de esa ciudad, quienes pedían altas obvenciones que los habitantes de trece pueblos se negaron a pagar en ese año ${ }^{2}$. El conflicto entre los moradores de esos trece pueblos del sur de Cuernavaca y los religiosos franciscanos fue tan profundo que los campesinos decidieron dejar de ir a escuchar misa; además, optaron por sepultar ellos mismos a sus muertos e, incluso, plantearon a las autoridades del Marquesado la posibilidad de irse y abandonar de manera definitiva sus pueblos. Esta última amenaza, finalmente, obligó a que las autoridades civiles actuaran en contra de la orden seráfica: se reestructuró la provincia franciscana para atender de manera distinta a los pueblos indígenas que se habían quejado. Lo interesante es que encontramos en ese expediente los documentos escritos en náhuatl desde los pueblos y, sobre todo, la carta que autoridades menores escribieron en la cárcel y que dirigieron a sus compañeros litigantes, en ese momento, ante la Real Audiencia y el arzobispo en la ciudad de México. Percibimos su aflicción, sus problemas, el vocabulario que utilizaban y las formas de dirigirse en náhuatl a sus compañeros.

En general, hay que subrayar el hecho de que en pleitos o juicios criminales también se pueden escuchar muy claramente las voces de los protagonistas que interesan. Por ejemplo, en el caso de mis intereses: las voces de los trabajadores de las haciendas - algunos residentes; otros, comuneros que iban y venían de sus pueblos-. También son numerosos los casos de controversias por malos tratos, usurpación de tierras, conflictos entre particulares o aquellos en los cuales los documentos nos permiten reconstruir la vida de campesinos que son explotados por las autoridades indígenas, mestizas o españolas vía el pago de diversos impuestos y del tributo personal 3 .

\footnotetext{
${ }^{2}$ AGN, Derechos Parroquiales, v. 1, e.1; Mentz, 2006, y ms. en prensa.

${ }^{3}$ Numerosos casos del AGN y del Archivo Municipal de Mazatepec en Mentz, 1988, y 1999, cap. 5.
} 
Incluso pueden escucharse las voces de los esclavos de una hacienda. En la segunda mitad del siglo XVIII ocurrió una "fuga de esclavos" del ingenio de Calderón, cercano a la actual ciudad de Cuautla. Ese expediente del AGN me permitió estudiar no sólo el incidente mismo de la "fuga" - que en realidad fue una marcha de protesta pacífica de los esclavos y de sus parientes libres- de este ingenio hacia la ciudad de México (Mentz, 1999, cap. 7) para pedir un "amo" mejor y más comprensivo que el nuevo que asumía la propiedad a la muerte del propietario anterior. La situación dramática que vivían los esclavos en general en los ingenios de azúcar, especialmente cuando estas empresas cambiaban de arrendatario o dueño, se vislumbra con especial claridad en este tipo de registros.

Los documentos criminales o las averiguaciones que exigen presentación de información por parte de testigos para el periodo virreinal son de especial interés para escuchar las voces que nos interesan. La mayoría de los documentos se encuentran en repositorios públicos como el AGN o el Archivo General de Indias (AGI). En esos textos se escucha la voz de los que presentan su testimonio en una forma relativamente poco alterada por los formalismos típicos de todo escrito oficial o notarial. Por la disposición legal española de dejar hablar con entera libertad al testigo para averiguar bien lo que sucedió, estamos ante transcripciones bastante fieles de lo dicho por ciertos protagonistas. Es decir, en esos casos podemos reconstruir lo sucedido desde la óptica del testigo; incluso es posible conocer las palabras que usó, su vocabulario para describir lo que vio o lo que ocurrió. Ese fue el caso en la "fuga" de esclavos del ingenio azucarero que relaté en un libro sobre el tema de Trabajo, sujeción $y$ libertad, en el que podemos oír la voz de los mismos esclavos involucrados (Mentz, 1999).

Las empresas también tienen sus archivos; en muchos casos conservan cuidadosamente la documentación. Por los intereses de sus dueños, dicha documentación por lo general se refiere a los títulos de propiedad, a los resultados de litigios y pleitos, es decir, a registros que, en caso de conflictos, puedan sustentar sus derechos de propiedad. No siempre se guardan los documentos respecto a las relaciones laborales, aunque sí, en muchos casos, los li- bros de caja y los de deudas de operarios. Para el estudio de los operarios y empresas mineras que me han interesado me referiré a dos casos. El primero trata de la empresa Vetagrande, en Zacatecas, cuyos documentos de los años 1788-1809 están en el archivo particular de una universidad de Texas; el segundo, de la empresa minera alemana que trabajó en México entre 1824 y 1838, que publicó en esos años sus informes para sus accionistas en Elberfeld, provincias prusianas del Rhin, en Alemania.

En la Biblioteca de la Universidad Metodista del Sur de Dallas, en Texas, se encuentran tres volúmenes llamados "Minas del Compromiso de Vetagrande, Zacatecas, 17881809 " 4 . Se trata de las cuentas y la correspondencia privada entre los administradores y el síndico procurador de los accionistas de una de las empresas mineras más grandes de la Nueva España, que permiten comprender muchos aspectos de la historia económica y social de México en general y, en particular, de las condiciones específicas de Zacatecas.

Los síndicos de accionistas de esta gran empresa minera residían en la ciudad de México y desde ahí supervisaban los trabajos de la empresa. Así, estos documentos revelan la forma de operar de la negociación, el papel del administrador general, cómo estaba organizada toda la empresa Vetagrande y cuáles fueron sus transacciones económicas con sus proveedores más importantes en la zona, así como en relación con la capital del reino. Se pueden apreciar también los problemas que en realidad afrontaba una negociación - no sólo las quejas expresadas ante el Estado-, así como las prácticas comerciales diarias. En general, los propietarios, administradores o empleados se expresan en los documentos privados con mayor sinceridad. En este caso, esa sinceridad se percibe claramente en las epístolas de sus administradores y en el libro de caja.

En las cartas se mencionan los gastos realizados en la extracción y el beneficio del mineral y se pueden observar, por ejemplo, las formas de pago, tema importante para conocer la circulación de moneda en esa época mo-

\footnotetext{
${ }^{4}$ Esta fuente paleografiada está en proceso de ser publicada íntegra por el Centro de Investigaciones y Estudios Superiores en Antropología Social (CIESAS). Mentz y Suárez (en prensa).
} 


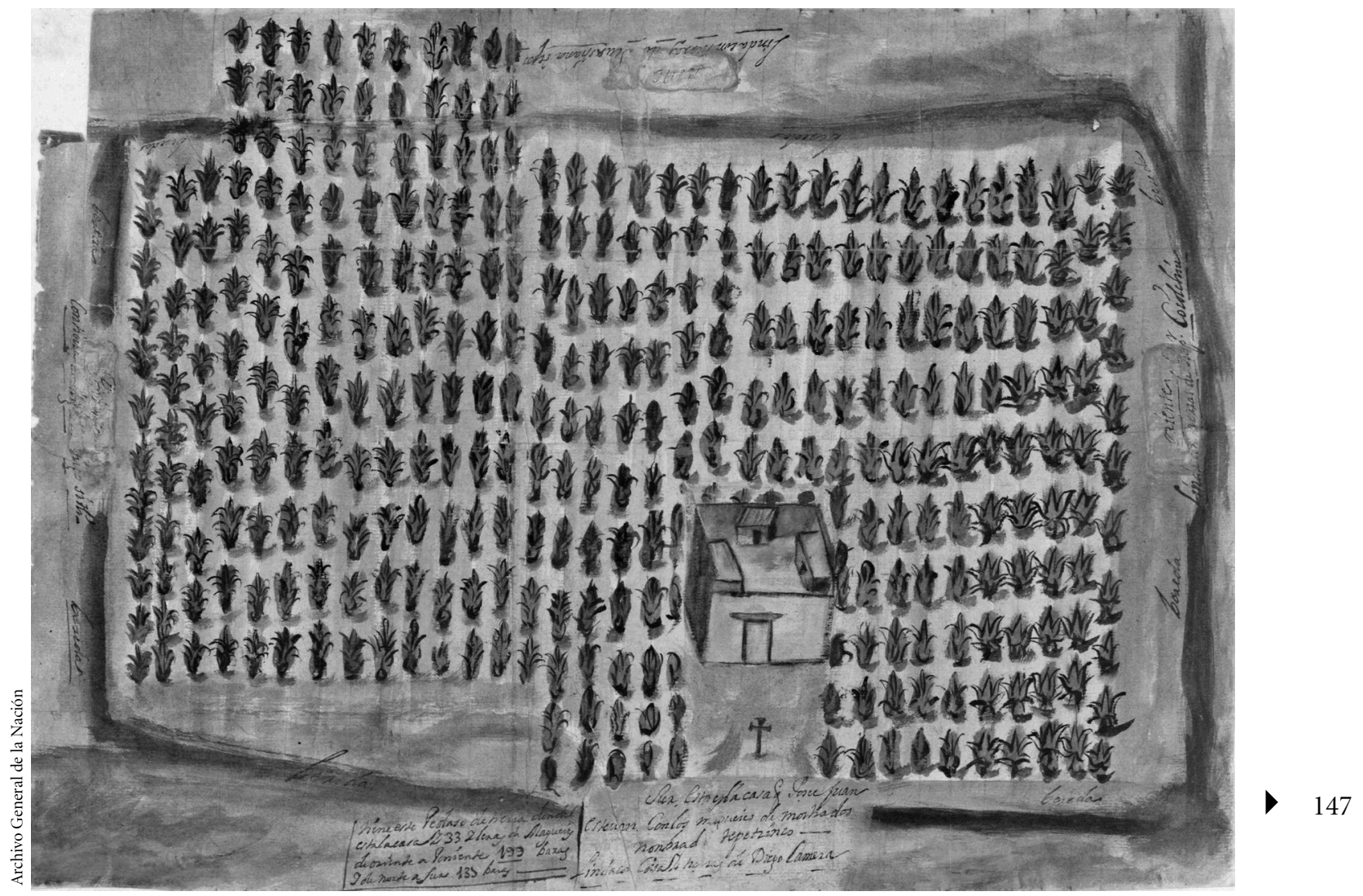

Tepetzingo, Cholula, Puebla, [1726]. Mapoteca, AGN.

nopolizada por las grandes casas de comercio. Así, en estos documentos se perciben las prácticas crediticias, los adelantos en dinero a proveedores y el pago en especie. También se puede analizar el funcionamiento de la tienda vinculada con la mina de Concepción y la relación con las casas de comercio de Zacatecas, México, Veracruz y de ultramar. De la misma manera se pueden observar en el libro de caja las relaciones laborales con administradores, barreteros, peones y artesanos. Por ejemplo, al herrero y a otros empleados se les pagaba "por obra"; el sacerdote, en cambio, cobraba mensualmente una limosna de 50 pesos.

Los gastos relacionados con los trabajadores en haciendas y minas se llevaban por separado en las "memorias" de cada unidad - fuera mina o hacienda-. Además, es de interés que en el libro de caja de esta empresa minera se apunten 55 pesos dados "a cuenta de las diligencias procesales formadas a la causa de los operarios de la mina Concepción". La entrada de esa foja lleva el título "Los operarios del robo de la mina Concepción", pero no sabemos más de ello. En cambio, sí tenemos la fecha en que se hizo ese gasto, lo que permitiría hacer una averiguación de lo ocurrido en otros archivos locales y de los juzgados de Zacatecas.

En el Archivo Histórico del Estado de Zacatecas gran cantidad de documentación permite complementar la información que se recaba en los archivos de las empresas, tanto para el periodo colonial como para el republicano. Así, en una lista de 1781 podemos observar a los operarios de minas y haciendas de Zacatecas a raíz de los "donativos" que todos tuvieron que entregar a la Corona de manera compulsiva. Esos datos nos permitieron realizar 
un análisis de la jerarquía interna y de las diferencias entre los numerosos empleados y operarios de las empresas zacatecanas (Mentz, 2003b).

En el caso de los libros de la empresa Vetagrande, por lo tanto, es de manera oblicua como podemos conocer la situación de los distintos operarios, peones, técnicos y administradores de esta importante empresa minera en Zacatecas entre 1788 y 1809 . Al conocer el contexto general del mundo de las minas y haciendas de beneficio de esa empresa en la que se desempeñaban esos operarios y esos expertos barreteros, azogueros, mineros mayores y demás amanuenses, podemos reconstruir sus carreras profesionales, su vida, sus preocupaciones. De manera similar — es decir, también oblicua — podemos observar a los trabajadores mineros que se relacionaron, ya en el periodo republicano, con la empresa alemana de minas que trabajó en México en los años 1824-1838.

El contexto político y económico de los años inmediatamente después de la Independencia atizó las ilusiones de inversionistas alemanes, a la par que ingleses, italianos, estadounidenses y otros, de invertir en la minería mexicana. Pensaban que sólo se requería de tecnología "moderna" proveniente de un país "avanzado" y "civilizado" (como el de ellos) para enriquecerse rápidamente y aprovechar las legendarias riquezas americanas. En las provincias prusianas del Rhin, en especial en Elberfeld, capitalistas de distintas zonas alemanas invirtieron en una empresa minera que debía operar en México en total hasta dos millones de pesos en ese ambiente de arrebatiña por las minas mexicanas. La compañía alemana adquirió minas en El Chico, Zimapán, Angangueo, Sultepec, pero los esfuerzos de los técnicos y expertos alemanes en México resultaron vanos ante su desconocimiento de las condiciones imperantes en el país. La dispersión del capital, los altos "alimentos" o renta que les exigieron los propietarios mexicanos de las minas, los problemas de transporte y obtención de fuerza de trabajo, las inundaciones y los problemas técnicos condujeron finalmente a que se desistiera de la explotación de las minas. Así, ya en la década de 1830, desilusionados, los accionistas dejaron de elevar el capital de la compañía y se declaró la bancarrota. Los informes a esos accionistas son de gran interés para la historia económica y laboral de México.
En esos informes publicados (que encontramos en bibliotecas y archivos en Alemania, en especial en Freiberg, Sajonia) y dirigidos a los accionistas (Generalbericht, 1825) se percibe la situación de la minería en los distritos en los que laboró la compañía y cómo sus agentes intentaron "modernizar" e innovar los trabajos en una época aún preindustrial también en los estados alemanes, que no se industrializaron sino hasta la segunda mitad del siglo XIX, entonces sí de manera vertiginosa. En la década de 1820 la compañía mandó a México a 51 alemanes, que constituyeron el personal de dirección, en un $25 \%$ aproximadamente. El grupo consistía sobre todo de mineralogistas, mineros mayores, administradores de minas al servicio del Estado prusiano, un experto en maquinaria y tres en topografía. Llegaron, además, un médico, once barreteros y mandones mineros, herreros, mecánicos, fundidores, un cantero, un experto en fuelles y cuero, un carpintero, cuatro albañiles y una pareja de sirvientes para atender la casa de la compañía.

Con respecto a los operarios mexicanos, la compañía tuvo experiencias diversas en las distintas zonas. Mientras que en El Chico, cerca de Pachuca, la competencia con los ingleses elevó mucho los salarios y las exigencias de los trabajadores - desde el punto de vista de los alemanes que redactaban los informes-, en la zona de $\mathrm{Zi}$ mapán alababan constantemente las buenas relaciones entabladas con los dóciles trabajadores otomíes. Información importante sobre las relaciones entre trabajadores de unas zonas y otras también se aprecia cuando los alemanes tuvieron especial dificultad, por ejemplo, para trasladar operarios de Zacualpan (Estado de México) a El Chico. En ese intento, la compañía construyó en El Chico casas para los trabajadores, luego los contrataron en Zacualpan y los trasladaron a esos caseríos. El resultado fue que, pocos meses después, la mayoría se regresó, siendo la razón primordial el hecho de que fueron agredidos ferozmente por la gente local de El Chico, que no permitió que fuereños realizaran el trabajo en sus minas y haciendas.

Es importante la información sobre la situación laboral en reales mineros que se percibe en los informes a los accionistas en Elberfeld. Por ejemplo, para los germanos eran nuevas las prácticas del pago del "partido"; es decir, 
del pago en especie, con una parte de la producción; práctica con la que los empresarios novohispanos habían contenido parcialmente los robos de mineral pues, de hecho, los barreteros se convertían en socios de los propietarios de la mina y cuidaban así con mucha atención el mineral argentífero extraído. Luego recibían su parte (el "partido") que beneficiaban de manera independiente. Es de interés que en esos años en los que los informes alemanes nos retratan la vida en los reales mineros, no se exigía en todos lados esta forma de pago, como en Sultepec y Angangueo por ejemplo. En contraste, resalta en esa fuente la insistencia de los operarios en El Chico por recibir en mineral su salario, es decir, en "partido", y su oposición a trabajar por turno con salario fijo de cuatro reales, lo que atrasó mucho los trabajos de la compañía, según dicen los informes.

La vigilancia del mineral y de la plata beneficiada era fundamental, cosa que los alemanes aprendieron rápidamente, pues mientras un alemán supervisor yacía enfermo en la capital perdieron en el mineral El Cristo, al sur de Sultepec, toda la plata extraída y beneficiada, por falta de precaución y vigilancia en la hacienda.

De manera similar a los libros de la empresa Vetagrande, estos informes alemanes de Elberfeld permiten conocer, por medio de las minuciosas memorias de gastos, los precios que en la década de 1820 tenían los insumos como bateas, cueros de res, costales, acero, pólvora, velas, paja, leña tejamanil, carbón, y de los salarios de cada uno de los numerosos y distintos grupos de operarios.

Para terminar, observemos algunos casos relacionados con fuentes que permiten conocer a los operarios mineros en épocas posteriores (Mentz, 2001). Obviamente no se puede encontrar directamente un legajo relacionado con el siglo XIX con el tema "operarios" o algo similar en el municipio de Sultepec, antiguo centro minero, o en Toluca, capital del Estado de México. Sin embargo, en el Archivo Municipal de Sultepec (AMS) sí hay cajas denominadas "Industria y Comercio", en las que se encuentran reportes sobre las compañías mineras que trabajaban en esa zona y donde se expresan los salarios que pagaban durante el periodo entre 1880-1910 a los peones, operarios menos calificados y operarios calificados en todas las empresas. Se pagaba entre 25 y 30 centavos a los primeros; a los segundos, 1.25 pesos. Sólo una empresa reportaba de manera excepcional el pago de 2.25 pesos como jornal más alto ${ }^{5}$. Esta información permite hacer comparaciones entre la vida de los operarios mineros en Sultepec y, por ejemplo, en El Oro, que vivía en esos años del Porfiriato una gran efervescencia modernizadora.

En el Archivo Municipal de Sultepec fue posible localizar contratos de trabajo escritos para el siglo XIX y así discernir las condiciones en las que laboraban los mineros en esta zona. Además, cuando hubo problemas con las empresas, el jefe político lo reportaba a la capital, por lo que en el ramo de Gobernación en el Archivo Histórico del Estado de México en Toluca (AHEM) encontramos la correspondencia que da cuenta de esos conflictos ${ }^{6}$.

En El Oro (también Estado de México), durante el Porfiriato, la situación laboral y política era especialmente conflictiva, como lo comprobamos en el mencionado archivo estatal, especialmente en 1905. Los consorcios habían reunido en este lugar a miles de trabajadores — no sólo cientos como en Sultepec-, lo cual implicaba problemas que iban desde numerosas arbitrariedades y extorsiones por parte de los capataces, hasta la insubordinación de operarios, así como agresiones, riñas y homicidios.

En el archivo estatal, en el fondo Gobernación, Seguridad Pública, encontré un extenso expediente denominado solamente "El Oro, 1905", que trata de las quejas de los parientes de los trabajadores mineros en esa ciudad que por "sorteo" fueron conducidos al ejército federal y llevados fuera de la zona ${ }^{7}$. De las cartas escritas —o dictadas - por lo general por mujeres, se desprende que se trataba de un método sistemático de represión a los insubordinados en las empresas, que se reportaban al jefe político. Éste simulaba un “sorteo" para seleccionar a los que debían servir en el ejército federal y, casualmente, la suerte siempre caía en un operario rebelde o insubordinado, o en un trabajador que en la cantina se había ex-

\footnotetext{
${ }^{5}$ AMS, Industria y Comercio, C. 2, e. II, C.3, e.VI, ss.

${ }^{6}$ Por ejemplo, el documento "Los trabajadores de las minas de la Negociación de Guadalupe, quejándose contra actos de los empleados de las mismas”, AHEM, Gobernación, v. 32,'Sultepec 1905', e. s. n.

${ }^{7}$ AHEM, Gobernación, Seguridad Pública, v. 38. 'El Oro, 1905 '
} 
presado contra la empresa o contra el gobierno local, o en un operario que se enfrentaba abiertamente a un capataz. Los documentos en ese archivo muestran con claridad ese sistema de castigar y "exiliar" mediante la leva al ejército porfiriano a cualquier disidente y, en especial, a los operarios insumisos de las empresas de El Oro; empresas a las que las autoridades locales servían de manera sumisa. Autoridades estatales y empresas actuaron de manera conjunta en urbes explosivas de proletarios, como El Oro, para lograr un control severo de la población y, en caso de protestas, una abierta represión. Les resultaban peligrosos los grandes conglomerados de peones, jornaleros, operarios, comerciantes, tenderos y demás sectores populares, pero para los estudiosos del pasado con frecuencia no es fácil documentar las sutiles formas que asumían las medidas represivas que se tomaban con discreción por parte del Estado.

Así, en este caso logramos escuchar en el archivo las voces de los familiares de los disidentes en El Oro, de las mujeres que buscaban a su consorte llevado a la fuerza por las tropas fuera de la región, de madres y de esposas cuyo hijo o marido había sido consignado arbitrariamente como soldado. Se trata de reclamos de numerosas familias que vivían el proceso de modernización y simultánea represión en el Porfiriato.

En muchos otros casos percibimos de la misma manera para siglos anteriores las voces de esclavos inconformes, de comuneros indígenas, de campesinos u operarios industriales que levantaron su voz; o inferimos de otros datos y registros cómo era su situación de vida y las condiciones concretas bajo las que laboraban diariamente. La pregunta planteada en el título de este escrito, por lo tanto, debe contestarse afirmativamente.

\section{Siglas}

AGN: Archivo General de la Nación AHEM: Archivo Histórico del Estado de México AMS: Archivo Municipal de Sultepec

\section{Bibliografía}

Durán, fray Diego, 1984, Historia de las Indias de la Nueva España e Islas de Tierra Firme, 2 vols., Miguel Ángel Porrúa, México.

Generalbericht, Erster, 1825, Generalbericht der Direktion des deutsch-amerikanischen Bergwerk-Vereins in Elberfeld an die Aktieninhaber, octubre de 1825, Büschler' schen Schriften, Elberfeld.

Mentz, Brígida von, 1988, Pueblos de indios, mulatos y mestizos. La protoindustrialización en el poniente de Morelos. 1770-1870, Ediciones de la Casa Chata, México.

—_, 1999, Trabajo, sujeción y libertad en el centro de la Nueva España. Esclavos, aprendices, campesinos y operarios manufactureros, siglos XVI a XVIII, Centro de Investigaciones y Estudios Superiores en Antropología Social, Miguel Ángel Porrúa, México.

_ 2001, "Trabajo minero y control social durante el porfiriato: los operarios de dos poblaciones contrastantes", Historia Mexicana, vol. L, enero-marzo, pp. 555-607.

_ catos, núm.12, otoño, Centro de Investigaciones y Estudios Superiores en Antropología Social, pp. 163-170.

—_, 2003b, "Educación técnica, reclutamiento de empleados y ascenso social en una empresa: el caso de la compañía minera de Vetagrande, Zacatecas, 1790-1840", en Brígida von Mentz (coord.), Movilidad social de sectores medios en México, Centro de Investigaciones y Estudios Superiores en Antropología Social, Miguel Ángel Porrúa, México, pp. 127-166.

, 2006, "La elaboración de matrículas poblacionales y el contexto social. Análisis de dos tradiciones estatales y de la relación entre registradores y registrados en la región de Cuernavaca (1540-1671)", en A. Molina y D. Navarrete (coords.), Problemas demográficos vistos desde la historia: análisis de fuentes, comportamiento demográfico y migración en México, siglos XVII-XIX, Centro de Investigaciones y Estudios Superiores en Antropología Social, El Colegio de Michoacán, México, pp. 29-66.

_- ms. en prensa, "Cambio social y cambio lingüístico. El 'náhuatl cotidiano', el de 'doctrina' y el de 'escribanía' en Cuauhnáhuac entre 1540 y 1671”, en Mercedes Montes de Oca y Claudia Parodi-Lewin (eds.), Visiones del encuentro de dos mundos en América: Lengua, cultura, traducción y transculturación en los albores de la colonia y después, Universidad Nacional Autónoma de México, Universidad de California, México, Los Ángeles, California.

— - y Clara Elena Suárez Argüello, en prensa, Epistolas de la empresa minera de Vetagrande, Zacatecas 1788-1809, Centro de Investigaciones y Estudios Superiores en Antropología Social, México. 